\title{
Capitate Bone
}

National Cancer Institute

\section{Source}

National Cancer Institute. Capitate Bone. NCI Thesaurus. Code C12856.

The largest of eight carpal bones, located in the center of the hand. 